\title{
AMEBOID MOVEMENTS IN MACROCYTES AND MEGALOBLASTS *
}

ROGER S. MORRIS, M.D., AND WILLIAM S. THAYER, M.D.

ST. LOUIS

BALTIMORE

Since the observations made by one of $\mathrm{us}^{1}$ of ameboid movements in a megaloblast, the opportunity has presented itself to study the fresh blood of five severe anemias.

In three of the bloods examined by us, ameboid motion was striking not only in many of the megaloblasts but also in the macrocytes. The absence of ameboid activity in the two remaining cases was probably attributable to the almost complete lack of unusually large cells in the blood. (For the blood findings, see the accompanying table.)

'Two of the bloods (Cases 1 and 2) were demonstrated to the class and the changes described below were observed by practically all of the ninety-odd students. In addition, we made prolonged observations on each of the bloods. Our specimens were sealed at once with petrolatum to prevent drying and to avoid currents in the plasma as far as possible.

In Case 1, preparations of the blood were studied during a megaloblastic crisis. The megaloblasts were quite numerous and were so frequently irregular in outline that they were found without difficulty with low magnification (Leitz ocular No. 3, objective No. 3). When examined under the oil immersion they often showed a striking change in form (Figs. 1-3, 7-10, 13-17, 18-22, 23-34, 51-66, 67-97, 103-105, 126-138), and at times, though not often, the change was so rapid that the successive alterations in shape could not be sketched. The phenomenon consists essentially of a change in form due (1) to small, often numerous, serrations in the outline of the cell which may later be smoothed out or which may develop into a large, prominent projection or pseudopod; or (2) to the protrusion of one or more blunt, rounded pseudopodia, often large, which may be accentuated by a constriction at the base; or (3) to a combination of these appearances at one time in the same cell. At times rather deep indentations appeared at one or more points on the rim of the cell. Sometimes these nicks appeared to be bridged over in part by a delicate, colorless film, showing at times a slight wrinkling, as if the coloring-matter were at this point retracting

* From the Clinical Laboratory the Johns Hopkins University and Hospital.

1. Thayer, W. S.: The Ameboid Activity of Megaloblasts, The Archives INT. MED., 1911, vii, 223. 
All drawings are made from specimens of fresh blood with Jeitz ocular No. 3 , objective 1/12" oil inmersion. The drawings are not made to scale. The numerals above each sketch denote the number of the sketch; those below, the time intervals.

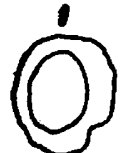

2:5T

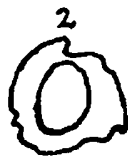

2:58

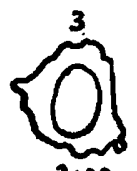

3:00

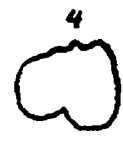

3:07

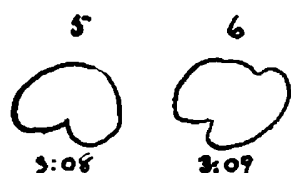

3:08

$3: 09$
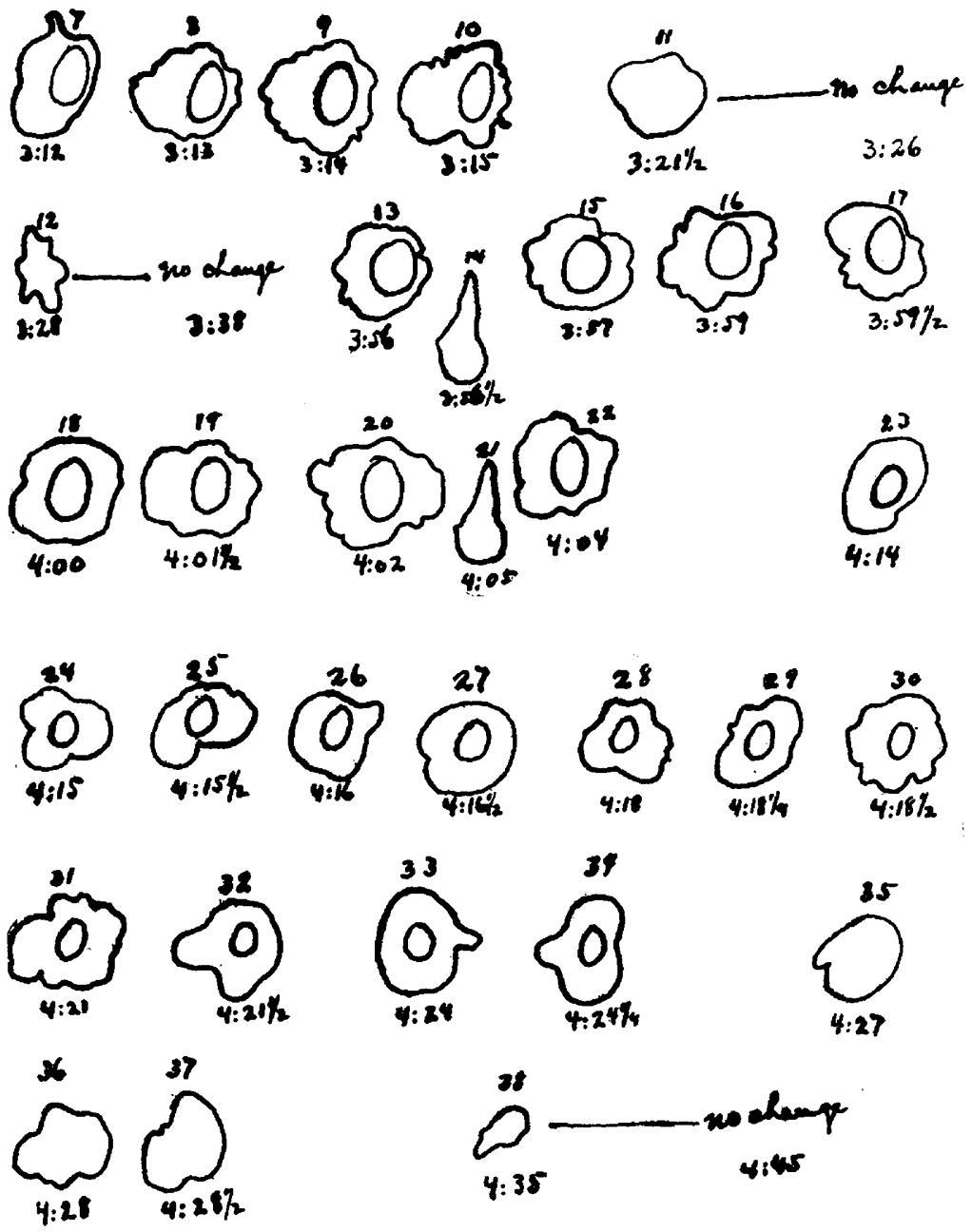

y: 35
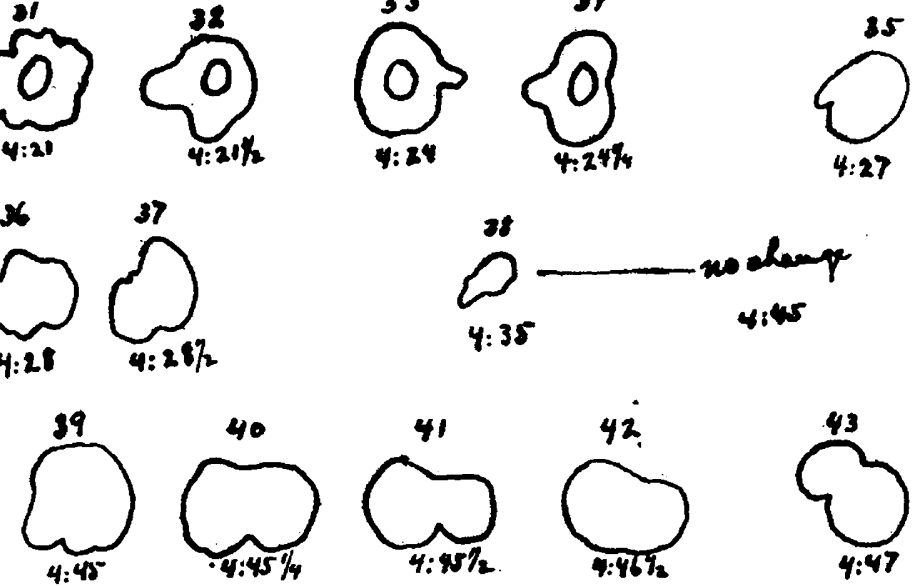

Figs. 1 to 3.-Case 1-Megaloblast. Figs. 4 to 6.-Case 1-Macrocyte. Figs. 7 to 10.-Case 1-Megaloblast. Fig. 11.-Case 1-Macrocyte. Fig. 12.-Case 1Poikilocyte. Figs. 13 to 22.-Case 1-Megaloblast. Figs. 14 to 21.-Case 1-A poikilocyte which showed no change during time of observation. Figs. 23 to 34.Case 1-Megaloblast. Figs. 35 to 37.-Case 1-Marocyte. Fig. 38.-.Case 1Poikilocyte (small). Figs. 39 to 45 .-Case 1-Macrocyte. 

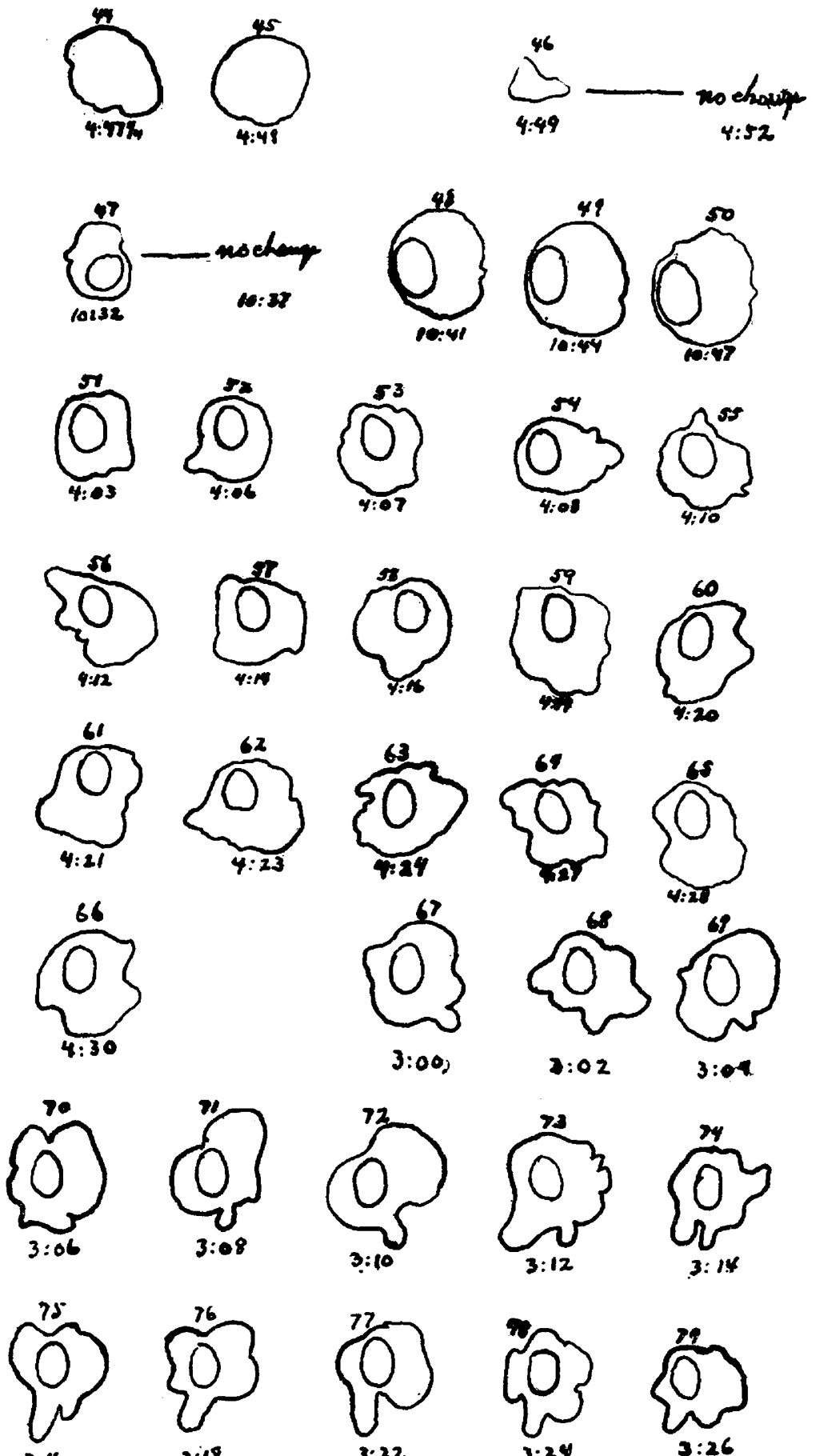

Fig. 46.-(ase 1-Poikilocyte (small). Fig. 47.-Case 1-Megaloblast. Figs. 4s to 50-Case 1-Megaloblast. Figs. 5l to 66.-Case 1-Megaloblast. Figs. 67 to 97.-Case 1-Megaloblast. 

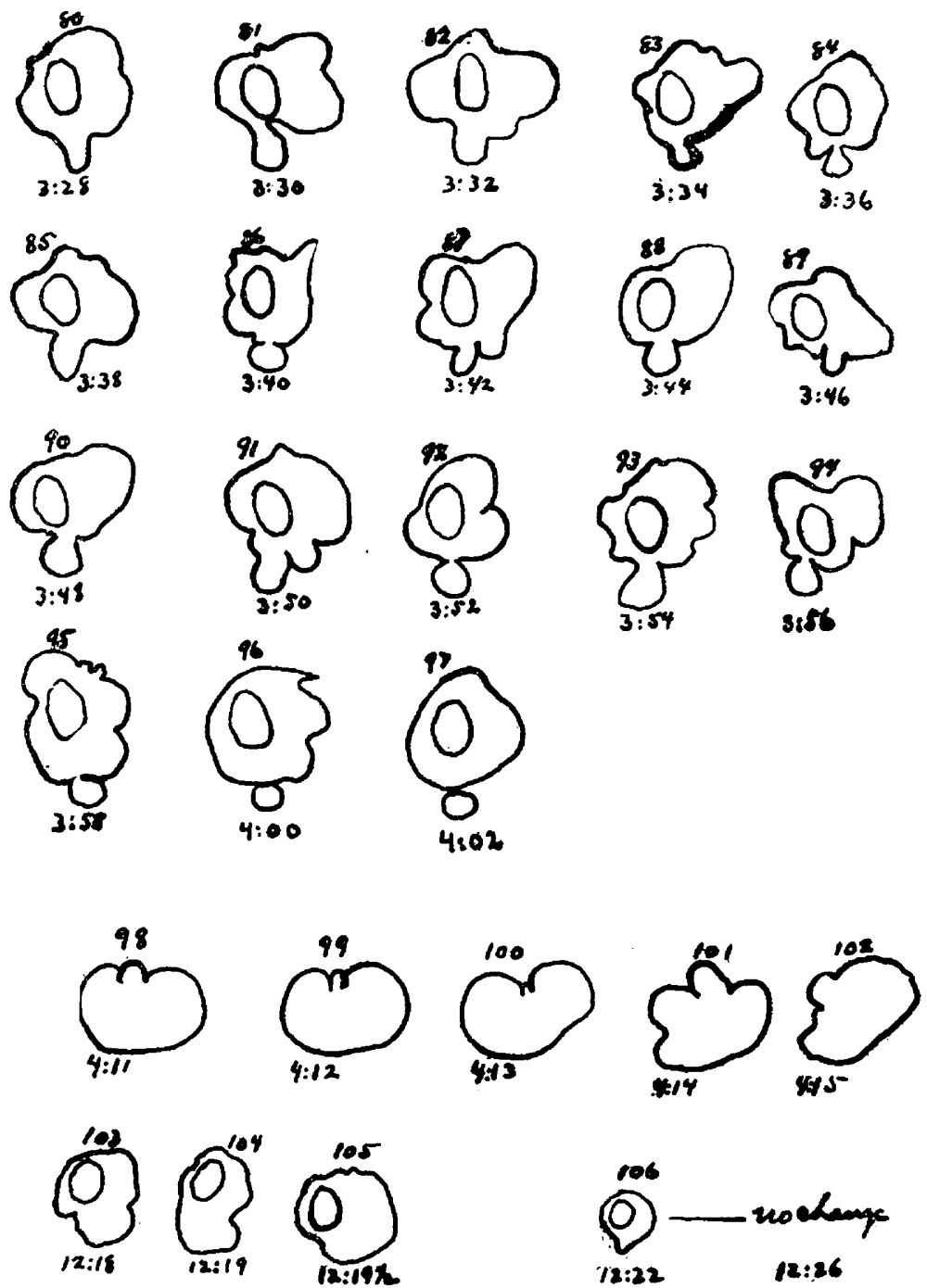

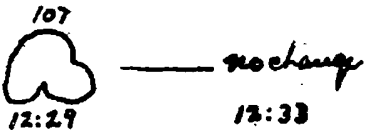
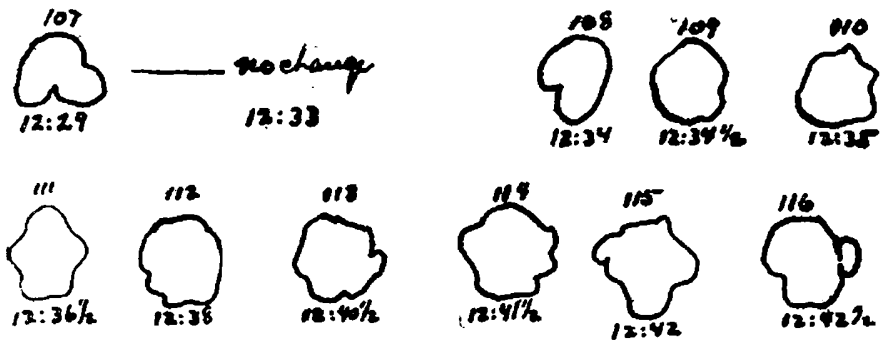

Figs. 98 to 102.-Case 1-Macrocyte (rather small). Figs. 103 to 105.Case 2-Intermediate. Fig. 106.-Case 2-Normoblast. Fig. 107.-Case 2-Poikilocyte. Figs. 108 to 112.-Case 2-Macrocyte. Figs. 113 to 118-Case 2.Macrocyte. 
from the stroma. Indentations such as these were often obliterated by very sudden movements, the colored substance springing back instantaneously and restoring the former contour of the cell or even forming a slight protrusion. The appearance at these points suggested somewhat

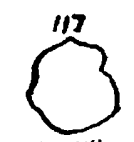

$12: 44$

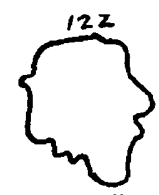

12: $32 \%$
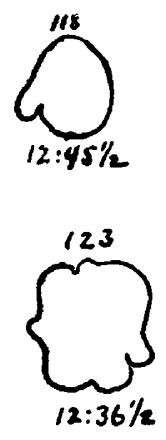
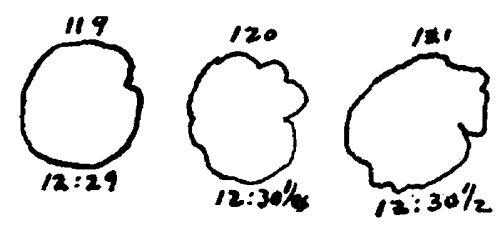

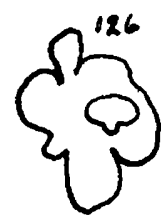

$12: 47 \%$

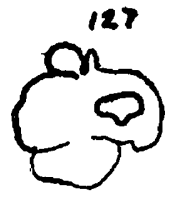

$12: 49 \%$
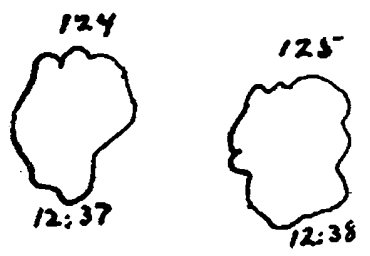

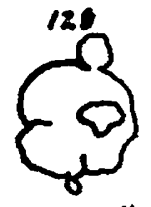

$12: 50 \%$

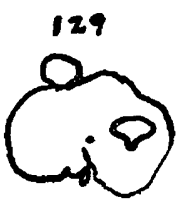

$12: 51$
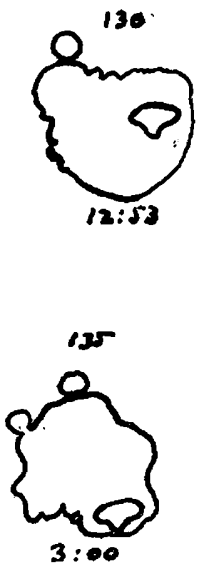

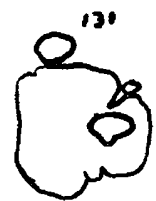

12:87
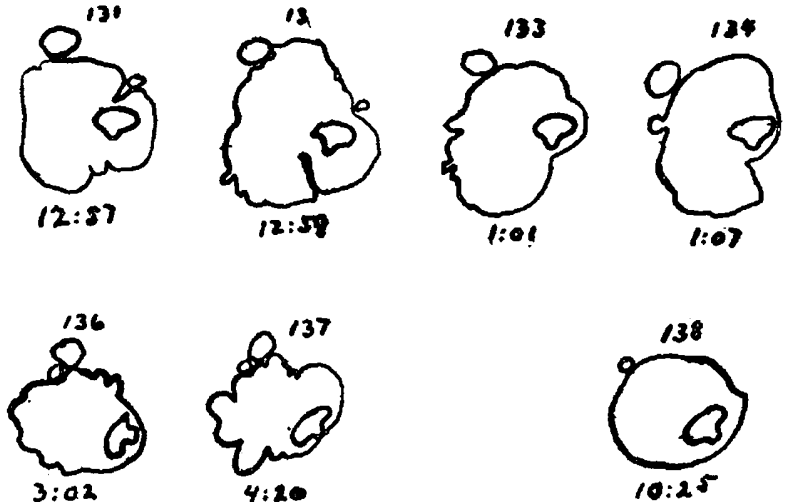

Figs. 119 to 125.-Case 3-Macrocyte. Figs. 128 to 138.-Case 3-Megaloblast. Fig. 138.-Case 3-The cell shown in drawings 126 to 137 , the following morning.

the appearance of some infected corpuscles in estivo-autumnal malaria in which the brassy-colored protoplasm recedes from the colorless outline of the cell. The malarial cells are, however, often deformed and obviously degenerated. But these motile elements showed no abnormal 
change in color or general appearance. No ccll, indeed, with a suggestion of creration or of the ordinary changes of shape observed in poikilocytes showed ameboid motion.

We have not been able to demonstrate propulsive motion in an ameboid cell, which remains practically in the same relative position during several hours' observation. In this respect the ameboid movement of the megaloblast differs from that often seen in the leukocytes. Indeed, the megaloblast protrudes its pseudopodium, only to retract it again. Inclusions or other evidences of phagocytosis in megaloblasts have not been seen.

Examination in Case 2 revealed the identical conditions observed in Case 1. Typical megaloblasts are not abundant, but normoblasts and intermediates are numerous. It is noteworthy that it is only the larger cells (megaloblasts and intermediates) which have shown unquestionable changes of form. In normoblasts (Fig. 106) we have not seen such alterations, though they have been looked for with considerable patience. Again, in Case 3, ameboid activity was very striking in the megaloblasts. Not all megaloblasts, of course, exhibit ameboid activity; and this is quite what one would expect from analogy with the leukocytes, some being inactive, others active.

That it is the large cells which are chiefly concerned in ameboid movements we have just seen. Further evidence in support of this fact is furnished by the results obtained in Cases 4 and 5 . Here, though the reductions in the number of erythrocytes were quite as great or even greater than in the preceding cases, the absence of very large red corpuscles was conspicuous. In Case 5 , in fact, no megaloblasts were seen at any stage of the disease, and they were scanty in Case 4 . In neither of these cases was active ameboid motion demonstrable in the red cells.

\section{AMEBOID ACTIVITY IN MACROCYTES}

The observations just recorded confirm the findings previously reported. ${ }^{1}$ In addition, we have observed exactly the same changes in shape in macrocytes (Figs. 4-6, 35-3\%, 39-45, 98-102, 108-112, 113-118, 119-125). The rapidity of change may be quite as great as in the nucleated red corpuscles and may present all the variations observed in the latter. There was no discoverable difference in kind or in degree. As in the case of the megaloblasts, not all of the macrocytes exhibit ameboid movements (Fig. 11). That non-nucleated cells should do so at all seems strange. But if the motility of the megaloblasts is in reality ameboidand to the writers there appears to be no other explanation-then there can be no doubt that certain macrocytes, too, are possessed of it. Numerous ameboid macrocytes were observed in the blood of Cases 1, 2 and 3 . A single, sluggish, rather small macrocyte was found in Case 5 in the 
examination of many specimens, this cell appearing at the time of the blood crisis.

To determine the effect of temperature, specimens were examined on the warm stage at body heat. It was impossible to see any difference in the ameboid activity of cells studied in this way and those at room temperature (about $70 \mathrm{~F}$. ).

Two specimens from Case 1 were allowed to stand over night, the one in the incubator at $37 \mathrm{C}$, the other at room temperature, both sealed, as in all instances, with petrolatum. On reexamination, about twenty hours after the specimens had been prepared, it was found that the red corpuscles were remarkably well preserved, little, if any, laking having occurred, though there were crenation in a few cells and endoglobular degenerations in many. The most striking fact noted was that it was no longer possible, as it had been when the smears were fresh, to select megaloblasts with low magnification, since nearly all of them were now circular or oval in outline and therefore less conspicuous. A sluggish, almost imperceptible change in form was observed in one megaloblast (Figs. 48-50), and in one only, though many megaloblasts and macrocytes were watched over considerable periods of time. In Case 3 , in a specimen of blood which had been prepared and sealed at 11 a. $\mathrm{m}$., a megaloblast, actively ameboid, was fixed in the field at about $12: 45$ p. m. It remained very active until 4:20 p. m., when the observations were temporarily interrupted. The following morning at $10: 25$, the cell was almost round (Fig. 138) and the ameboid activity had entirely ceased. This megaloblast showed no endoglobular degeneration and no apparent loss in color. Its nucleus, as is the rule in such cells, showed practically no change in shape throughout the observations (Figs. 126138). In these specimens examined after twenty or more hours, the leukocytes also showed a cessation of ameboid activity, though, unlike the red corpuscles, they frequently retained their irregular shape.

The cells, both megaloblasts and macrocytes, exhibiting ameboid movements were for the most part well colored, many seeming to be richer in hemoglobin than the average cell. A few, paler than the majority of the surrounding reds, were seen to change form, but no difference was determined in the motion of such cells and those more highly colored. No suggestion of crenation was observed in the ameboid cells. That the alterations in shape observed were not the result of osmosis is made probable by the absence of shadows or crenated erythrocytes in the neighborhood of those studied, and, further, by the fact that smaller red cells and many which were large remained immobile.

Many poikilocytes and normocytes were studied. In no case was there the least evidence of change in form while they were under observa- 
tion. (Figs. 12, 14, 21, 38, 46, 107). Rolling of the cells was, of course, excluded. Currents were practically eliminated by sealing the specimens.

It occurred to us that it might be possible to demonstrate protoplasmic currents in the ameboid red cells by means of the so-called vital staining methods. It is the young cells which have shown ameboid activity and in these cells particularly, as Vaughan ${ }^{2}$ and others have shown, the reticulofilamentous substance is demonstrable. The dyes used were Unna's polychrome methylene blue and neutral red in physiologic salt solution. Of the bloods possessing ameboid red cells, only that from Case 3 was studied in this manner. There was no difficulty in finding macrocytes and megaloblasts with well-stained reticula but in none of them could we see even a suggestion of ameboid movements, though control preparations made at the same time, unstained, contained very active ameboid cells. The neutrophilic leukocytes retained their ameboid activity well in the vitally stained specimens. Though our experiments with vital staining are limited to one case, it seems probable that the staining solutions used abolish the ameboid movements of red cells. This is all the more likely, since there is no description in literature of active movements of the vitally stained particles in erythrocytes, so far as we can discover.

The movements which we have described in macrocytes and megaloblasts were similar to those which were observed in the first case reported, but the protrusion and coalescence of small pseudopods were not so strikingly evident and the similarity of the movements to those of leukocytes not so apparent. The megaloblast originally described was a large, pale form, apparently a very immature cell, while, as has been said, these megaloblasts and macrocytes were all corpuscles of quite the normal color.

As a probable evidence of ameboid activity in megaloblasts, the occasional irregularity in outline seen in stained blood films may be recalled.

That ameboid activity in the red corpuscles may have considerable biologic significance is made clear by recalling the theories advanced to explain leukocytoses. It is not improbable that the "blood crises" are due to an active wandering out of the red cells from the marrow, the result of some unknown stimulus. Should this prove to be the case, it is likely that it will be found to be a departure from the normal, an unusual method of responding to increased normal or pathological stimulus, though for the fetus this may well be physiological. As yet, however, we have been unable to study blood from the fetus.

2. Vaughan, V. C., Jr.: The Appearance and Significance of Certain Granules in the Erythrocytes of Man, Jour. Med. Research, 1903, x, 342. 
The counts given below coincide with the dates of examination.

CAse 1.--E. D. P., male, aged 41, white, med. No. 26,575, admitted to the hospital Nov. 22, 1910. Diagnosis: Pernicious anemia; erysipelas; streptococcus septicemia.*

Dec. 1, 1910: Blood examination:

Red blood-cells, 900,000.

Hemoglobin, 20 per cent.

White blood-cells, 8,100 .

Differential count of 402 cells gave:

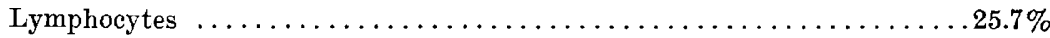

Large mononuclears and transitionals.................. $4.7 \%$

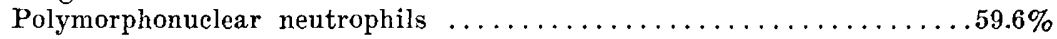

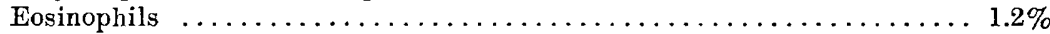

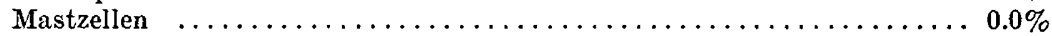

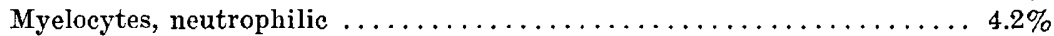

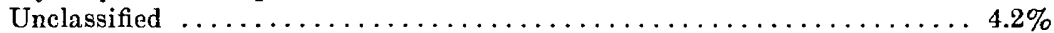

In counting the leukocytes, 40 megaloblasts, 36 intermediates, and 24 normoblasts were seen.

The red cells showed marked anisocytosis and poikilocytosis. There were many large cells. The stained film revealed polychromatophilia, basophilic granulation, nuclear particles, and Cabot's ring bodies in large numbers. Marked signs of regeneration were, therefore, present.

CASE 2.-J. S., male, aged 17, colored, med. No. 26,868, admitted Jan. 25, 1911. Diagnosis: Severe anemia (pernicious?).

Feb. 21, 1911: Blood examination:

Red blood-cells, 1,750,000.

Hemoglobin, 38 per cent.

White blood-cells, 21,000.

Differential count of 800 cells gave:

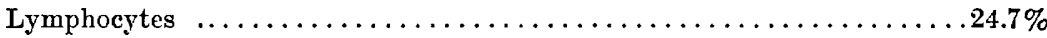

Large mononuclears and transitionals .................. $8.7 \%$

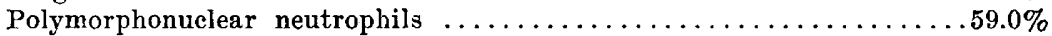

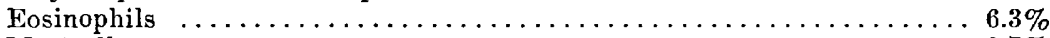

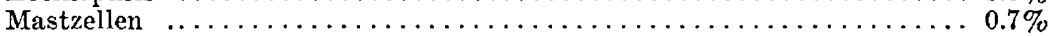

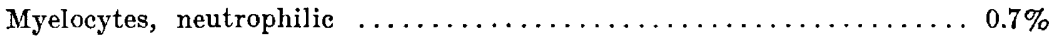

Nucleated red cells were present in the proportion of 350 to 1,000 white cells, normoblasts predominating. There were considerable anisocytosis and poikilocy. tosis. Macrocytes were numerous but were not so large as in the preceding case. A Romanowsky stain showed much the same changes in the erythrocytes as in Case 1 , but to a less degree, though the nucleated forms were more common.

Cass 3.-T. P. J., male, aged 43, white, med. No. 27,438, admitted May 28, 1911. Diagnosis: Pernicious anemia.

June 16, 1911 : Blood examination:

Red blood-cells, 1,544,000.

Hemoglobin, 33 per cent.

White blood-cells, 3,200.

Differential count:

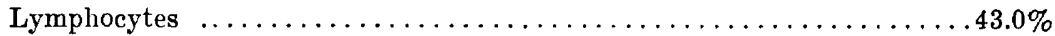

Large mononuclears and transitionals................... $4.0 \%$

Polymorphonuclear neutrophils $\ldots \ldots \ldots \ldots \ldots \ldots \ldots \ldots \ldots \ldots \ldots \ldots \ldots$

*The infection occurred about one month after the present study of the blood was made. 
Nucleated reds were present in the proportion of 230 to 1,000 leukocytes. Poikilocytosis and anisocytosis were marked, some of the cells being unusually large. The evidences of regeneration of the red cells were striking.

CAsE 4.-H. M., male, aged 45, white, med. No. 27,336, was admitted May 4. 1911. Diagnosis: Aplastic pernicious anemia (autopsy).

May 4, 1911: Blood examination:

Red blood-cells, $1,280,000$.

Hemoglobin, 20 per cent.

White blood-cells, 1,200 .

Differential count of 100 cells :

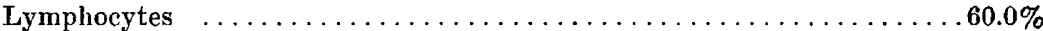

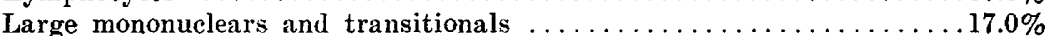

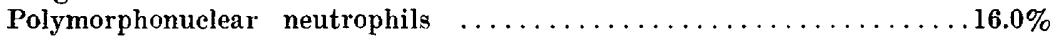

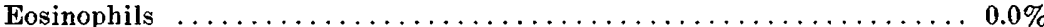

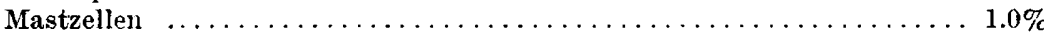

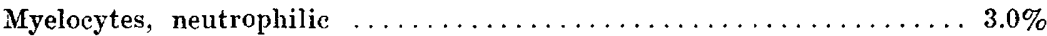

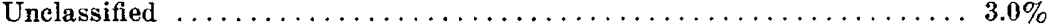

Two megaloblasts and one normoblast were found. The blood showed a considerable degree of anisocytosis and poikilocytosis but the absence of many macro. cytes and, indeed, of any very large ones was striking, the morphology of the cells suggesting a severe secondary rather than a primary pernicious anemia, except for the megaloblasts. Aside from the scanty nucleated reds, there were no signs of regeneration in the red cells. The occurrence of myelocytes and a few nucleated red corpuseles indicates a futile attempt at regeneration.

CASE 5.-P. H., male, aged 56, white, med. No. 27,337, was admitted May 4, 1911. Diagnosis: Severe secondary (toxic) anemia (?), pernicious anemia (?). (The patient was employed in a dye factory and it is possible that the anemia was the result of his occupation; conclusive evidence is not yet at hand.)

June 7, 1911 : Blood examination:

Red blood-cells, 900,000 .

Hemoglobin, 15 per cent.

White blood-cells, 2,400 .

Differential count:

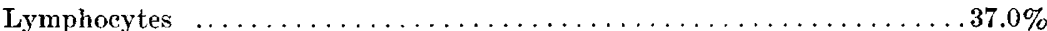

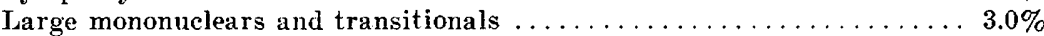

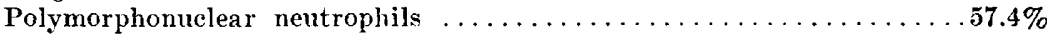

Eosinophils .............................. $2.0 \%$

Mastzellen ............................... $0.0 \%$

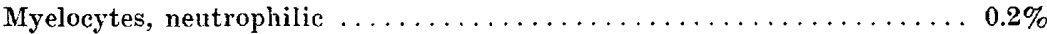

No nucleated reds were found and there were no other evidences of regeneration of the red corpuscles. The absence of large cells is striking. Except for the lack of nucleated red cells and the presence of only slight poikilocytosis the blood bore a striking resemblance to that of Case 4. On vital staining with polychroms methylene blue, very few erythrocytes showed the reticulo-filamentous substance. After the red count had fallen to 530,000 , defibrinated blood was given intravenously by Dr. W. L. Moss (who will include the case in a forthcoming report), and on June 13, 1911, an examination of the blood showed:

Red blood-cells, 1,580,000.

Hemoglobin, 19 per cent.

White blood-cells, 4,000.

There was now a normoblastic crisis, 143 nucleated red cells per 1,000 whites. No megaloblasts were found and the intermediates were small.

1806 Locust Street. St. Couis -406 Cathedral Street, Baltimore. 